\title{
Lauki-sareko patroiak kalkulatzea, Pólyaren teoriaren eskutik
}

\section{(Counting squared grid patterns with Pólya Theory)}

\author{
María Merino Maestre ${ }^{1 *}$, Imanol Unanue Gual ${ }^{1}$ \\ ${ }^{1}$ Matematika Aplikatua eta Estatistika eta Ikerkuntza Operatiboa \\ Zientzia eta Teknologia Fakultatea (UPV/EHU) \\ *maria.merino@ehu.eus
}

DOI: $10.1387 /$ ekaia.17851

Laburpena: Lan hau Yurramendiren (2013) eta Merino eta Yurramendiren (2014) artikuluen jarraipena da. Horietan, formula matematiko batzuk eman ziren kalkulatzeko zenbat patroi bitar ez-baliokide diren lauki-sarean. Lan honen helburua formula matematiko horiek eta haien orokorpenak Burnside eta Pólyaren zenbatzeko teoriaren bidez azaltzea da. Izan ere, bi kolore baino gehiago duten patroiak zenbatuko ditugu eta, gainera, kolore guztien maiztasuna jakinda, patroi ez-baliokideen kopurua lortzeko bidea emango dugu. Artikulu hau UPV/EHUko Imanol Unanue Gualen Matematikako Gradu Amaierako Lanean oinarrituta dago.

Hitz gakoak: Burnsideren teoria, Pólyaren teoria, matrize baliokideak, OEIS, simetria.

\begin{abstract}
This work is a sequel of papers Yurramendi (2013) and Merino and Yurramendi (2014), where some mathematical formulae for counting the number of non equivalent binary rectangular grids have been obtained. The aim of this work is the explanation and generalization of those mathematical formulae based on Burnside and Pólya's theory of counting. Grids with more than two colors are calculated and, moreover, for known occurrencies of all the colors, the way for obtaining the non-equivalent grids number is shown. This article is based on the Mathematics Final Degree Dissertation by Imanol Unanue Gual from UPV/EHU.
\end{abstract}

Keywords: Burnside's theory, Pólya's theory, equivalent matrices, OEIS, symmetry. 


\section{SARRERA}

Aurkeztuko dugun problemaren motibazioa bizitza errealeko egoera batzuekin erlazionatuta dago. Azal dezagun gaur egungo horietako bat: txartelak. Txartelen erabilera gero eta hedatuago dago; hoteleko logelen ateak irekitzeko, edo autobideen bidesarietan, garraiobide batzuetan edo parkimetroetan ordaintzeko, besteak beste.

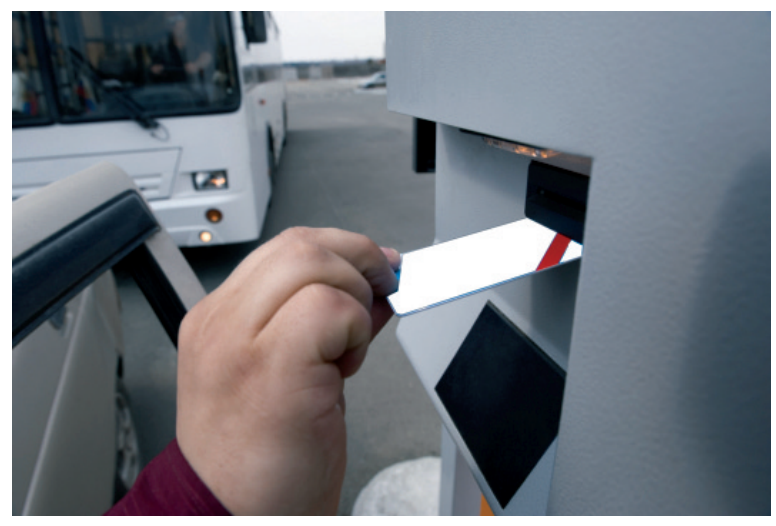

Imajina dezagun autoa aparkaleku batera sartzeko lauki-sareko txartela diseinatu nahi dugula. Parkimetroan sartzea errazteko asmoz, posible da txartela edozein posiziotan sartzea, parkimetroaren zirrikituaren neurria ( $r$ laukiko luzerakoa) kontuan izanik; hau da, txartela laukizuzena bada, lau aukera dugu era arrakastatsuan sartzeko, 1. adibideko irudian ikusten den bezala. Bi txartel elkarren berdinak dira baldin txartel batetik (a txartela) bestera honela pasa badaiteke: txartela 180 gradu biratuz (b), aurrealdetik atzealdera itzulia emanez (c) edo bien konbinaketa eginez (d). Erantzun nahi diegun galderak mota honetakoak dira: zenbat txartel desberdin egin liteke bi kolore erabiliz? Eta zehatz-mehatz hiru lauki beltzez eta gainontzeko laukiak zuriz margotzen badira? Eta kolore gehiago erabiliz? Eta txartela karratuak kontsideratzekotan?

Problema modelizatzeko nahian, txartelak matrize moduan ikusiko ditugu. Izan bitez $r, s$ eta $t$ zenbaki arruntak. Orduan, gure lanaren interesa $t$ kolore erabiliz $r \times s$ eta $r \times r$ tamainako matrize ez-baliokideak zenbatzean datza. Kopuru horiek matrize orokorren eta karratuen kasuetan $a(r, s ; t)$ eta $b(r ; t)$ notazioarekin adieraziko ditugu, hurrenez hurren. Bi matrize baliokide direla esango dugu baldin eta berdinak badira islapenak (horizontalak zein bertikalak) edo biraketak (180 graduen multiploak laukizuzenen kasuan, edo 90 graduen multiploak karratuen kasuan) egin ondoren. Argi dago lerro kopurua eta zutabeena berdinak direnean (matrize karratuak, hain zuzen ere) simetria gehiago definitzen ahal direla desberdinak 
direnean baino. Beraz, bi egoera bereiziko ditugu: matrize laukizuzenak eta matrize karratuak $(r=s)$. Gainera, ikusiko dugunez, emaitzak $r$ eta $s$ neurrien bikoitasunaren menpekoak izango dira.

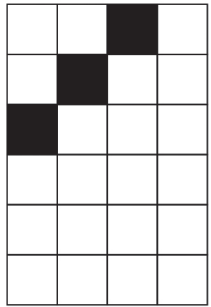

(a)

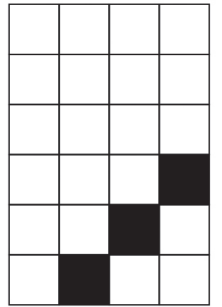

(b)

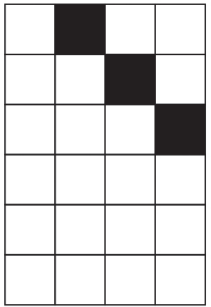

(c)

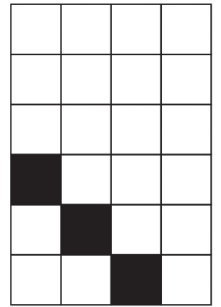

(d)

1. irudia. Parkimetroan txartela sartzeko aukera posibleak.

Lan honen jatorria hurrenez hurren EKAIA 26 eta EKAIA 27 aldizkarietan agertutako bi artikulu dira [1,2]. Lehenengoan, konputazioa erabiliz formula batzuk induzitzen dira; bigarrenean, oinarrizko konbinazioa erabiliz aieru batzuen froga matematikoa erakusten da. Hirugarrenean - honako honetan, alegia - , Pólyaren zenbatzeko teoria erabiliko da formulak lortzeko eta orokorpenak egiteko. Aipatutako lanetan, patroi bitarrak landu dira, hots, bi elementuko edo bi koloreko matrizeen kalkulua. Matrize orokorren kasuan, (1) adierazpenean dugu formulen laburpena:

$$
a(r, s ; 2)= \begin{cases}\frac{1}{4}\left(2^{r s}+3 \cdot 2^{\frac{r s}{2}}\right), & r \text { bikoitia, } s \text { bikoitia } \\ \frac{1}{4}\left(2^{r s}+2^{\frac{r s+s}{2}}+2 \cdot 2^{\frac{r s}{2}}\right), & r \text { bakoitia, } s \text { bikoitia } \\ \frac{1}{4}\left(2^{r s}+2^{\frac{r s+r}{2}}+2 \cdot 2^{\frac{r s}{2}}\right), & r \text { bikoitia, } s \text { bakoitia } \\ \frac{1}{4}\left(2^{r s}+2^{\frac{r s+r}{2}}+2^{\frac{r s+s}{2}}+2^{\frac{r s+1}{2}}\right), & r \text { bakoitia, } s \text { bakoitia }\end{cases}
$$

Eta matrize karratuen kasuan, (2) adierazpenean:

$$
b(r ; 2)= \begin{cases}\frac{1}{8}\left(2^{r^{2}}+2 \cdot 2^{\frac{r^{2}}{4}}+3 \cdot 2^{\frac{r^{2}}{2}}+2 \cdot 2^{\frac{r^{2}+r}{2}}\right), & r \text { bikoitia } \\ \frac{1}{8}\left(2^{r^{2}}+2 \cdot 2^{\frac{r^{2}+3}{4}}+2^{\frac{r^{2}+1}{2}}+4 \cdot 2^{\frac{r^{2}+r}{2}}\right), & r \text { bakoitia }\end{cases}
$$


Aurreko emaitzak berriro frogatzeaz gain, teoriari esker, formula horiek bi arlotan orokortuko ditugu: (i) patroi bitarrak erabiltzetik $t$ koloreko patroi ez-baliokideen kopurua kalkulatzera joanez, eta (ii) kolore bakoitzaren maiztasuna jakinik, patroi ez-baliokideen kopurua lortzeko bidea emanez. Lan honetan azalduko diren emaitzetan oinarrituta, hogeita hamar segida onartuak dira The On-Line Encyclopedia of Integer Sequences (OEIS) webgunean. (Zenbaki arrunten, zatikien, zenbaki transzendenteen digituak eta zenbaki konplexuen segidak dituen online entziklopedia da OEIS, [3] estekan kontsulta daitekeena; Neil James Alexander Sloane matematikaria hasi zen biltzen 1960ko urteetan, eta 2018an 300.000 segida inguru ditu: mota honetako datu-base handiena da.)

Lan hau honela dago antolatuta: 2. atalean, Burnside eta Pólyaren teoria beharrezkoa erakutsiko da; 3. atalean, lauki-sareko patroien kalkulua azalduko da; 4. atalean, matrize karratuen kasua aztertuko da; bukatzeko, 5. atalean, ondorioak ikus daitezke.

\section{BURNSIDE ETA PÓLYAREN TEORIA}

Aipatu dugunez, gure problemaren emaitzak orokortzeko, Burnsideren lema eta Pólyaren teoremak erabiliko ditugu (ikusi $[4,5,6]$ ), eta horiek frogatu aurretik, zenbait emaitza lagungarri frogatuko ditugu $([7,8,9]$ etan matematika diskretuaren erreferentziak ikus daitezke, eta $[10,11,12]$ etan, talde teoriarenak). Hasteko, hiru multzo kontsideratu behar ditugu:

- $I$, elementuen multzoa. $I$-ko elementuak gure problemen osagaiak deskribatzeko erabiliko ditugu, $I=\left\{i_{1}, \ldots, i_{n}\right\}$. I-tik $I$-ra doazen bijekzioei simetriak edo permutazioak deituko diegu.

$-G, I$-ren gaineko simetrien taldea, $G=\left\{g_{1}, \ldots, g_{|G|}\right\}$. Talde simetrikoa, $S_{n}$, permutazio guztien taldea da. $G$ taldeko elementu bakoitzak permutazio bat induzitzen du.

- $K$, koloreen multzoa. $K$-ko elementuei kolore deituko diegu, $K=\left\{k_{1}, \ldots, k_{t}\right\}$.

Azalduko dugun teoria ulertzeko, ezinbestekoa da talde teoriaren oinarrizko emaitza hau ezagutzea: $S_{n}$-ko edozein permutazio ziklo disjuntuen biderkadura gisa adieraz daiteke.

1. Definizioa. Izan bitez $G$ I-ren simetrien taldea eta $i_{0} \in I$. Orduan, $G$-rekiko $i_{0}$-ren orbita $G$-ko simetrien gaineko $i_{0}$-ren irudien multzoa da, $O_{G}\left(i_{0}\right)$ adierazirik:

$$
O_{G}\left(i_{0}\right)=\left\{g\left(i_{0}\right) \mid g \in G\right\} .
$$


Lauki-sareko patroiak kalkulatzea, Pólyaren teoriaren eskutik

Ohartu $\sigma \in S_{n}$ permutazio bat hartuz gero, $G=(\sigma)$ taldeak $I=\{1,2, \ldots, n\}$ multzoaren gainean dituen orbitak $\sigma$-ren ziklo bakoitzean agertzen diren elementuak direla. Adibidez, $\sigma=\left(\begin{array}{cccccc}1 & 2 & 3 & 4 & 5 & 6 \\ 2 & 3 & 1 & 4 & 6 & 5\end{array}\right)=$ $=(123)(4)(56) \in S_{6}$ permutazioa hartuta, $G=\langle\sigma\rangle$ taldean hiru orbita daude: $O_{G}(1)=\{1,2,3\}, O_{G}(4)=\{4\}$ eta $O_{G}(5)=\{5,6\}$.

2. Definizioa. Izan bitez G I-ren simetrien taldea eta $J \subseteq I$. Orduan,

$$
\varepsilon_{G}(J)=\{g \in G \mid g(j) \in J, \forall j \in J\}
$$

simetria multzoari G-rekiko J-ren egonkortzailea deituko diogu.

3. Definizioa. Izan bedi g I-ren gaineko simetria eta $i_{0} \in I$. Orduan, $i_{0} g$-ren puntu finkoa dela esango dugu baldin eta $g\left(i_{0}\right)=i_{0}$. Are gehiago, $g$ simetriak finko uzten dituen I-ko elementu guztien multzoari g-ren puntu finkoen multzoa deitzen zaio:

$$
F(g)=\{i \in I \mid g(i)=i\} .
$$

1. Proposizioa. $G$ simetrien taldeak I-ren baliokidetasun erlazioa definitzen du:

$$
i_{1} \sim i_{2} \Leftrightarrow \exists g \in G: g\left(i_{1}\right)=i_{2} \Leftrightarrow O_{G}\left(i_{1}\right)=O_{G}\left(i_{2}\right) .
$$

Froga. Propietate erreflexiboa, simetrikoa eta iragankorra betetzen dira.

2. Korolarioa. Izan bitez G I-ren simetrien taldea eta $i_{1}, i_{2} \in I$. Baldin eta $O_{G}\left(i_{1}\right)$ eta $O_{G}\left(i_{2}\right)$ multzoen arteko ebakidura ez-hutsa baldin bada, orduan $O_{G}\left(i_{1}\right)=O_{G}\left(i_{2}\right)$. Beraz, G-ren gaineko (desberdinak diren) orbitek $I$ ren partiketa bat osatzen dute.

Froga. Aurreko emaitzaren aplikazioa da.

3. Proposizioa. Izan bedi $i \in I$. Orduan, $j \in$ I guztietarako,

$$
|\{g \in G \mid g(i)=j\}|= \begin{cases}\left|\mathcal{E}_{G}(i)\right|, & \text { baldin } j \in O_{G}(i) \\ 0, & \text { baldin } j \notin O_{G}(i)\end{cases}
$$

Froga. Nabaria denez, $j \notin O_{G}(i)$ bada, ez da existitzen $g(i)=j$ betetzen duen $g \in G$ simetriarik. Orduan, $|\{g \in G \mid g(i)=j\}|=0$. Bestela, $j \in O_{G}(i)$ bada, $\exists g \in G: g(i)=j$. Har dezagun $A=\{g \in G \mid g(i)=j\}$ eta froga de- 
zagun $|A|=\left|\varepsilon_{G}(i)\right|$. Horretarako, sor dezagun $\chi: A \rightarrow G$ aplikazioa, non $\chi(h):=g^{-1} \circ h$ den. Ikusten denez,

$$
[\chi(h)](i)=\left(g^{-1} \circ h\right)(i)=g^{-1}[h(i)] \stackrel{h \in A}{=} g^{-1}(j) \stackrel{g(i)=j}{=} i \Rightarrow \chi(h) \in \mathcal{E}_{G}(i) .
$$

Beraz, $\chi A$-tik $\varepsilon_{G}(i)$-ra doan aplikazioa da. Bestalde, $\forall f^{\prime} \in \varepsilon_{G}(i)$, $\exists ! h^{\prime} \in A: \chi\left(h^{\prime}\right)=f^{\prime}$. Izan ere,

$$
\begin{gathered}
\chi\left(h^{\prime}\right)=f^{\prime} \Leftrightarrow g^{-1} \circ h^{\prime}=f^{\prime} \Leftrightarrow h^{\prime}=g \circ f^{\prime} \in G \text { eta } \\
h^{\prime}(i)=\left(g \circ f^{\prime}\right)(i) \stackrel{f^{\prime} \in \mathcal{E}_{G}(i)}{=} g(i)=j \Rightarrow h^{\prime} \in A .
\end{gathered}
$$

Ondorioz, aplikazioa bijektiboa da, eta $|A|=\left|\varepsilon_{G}(i)\right|$.

4. Proposizioa. $i \in I$ guztietarako, $|G|=\left|O_{G}(i)\right|\left|\varepsilon_{G}(i)\right|$.

Froga. Har dezagun $i \in I$ elementu finko bat, eta sor dezagun honako aplikazio hau:

$$
\begin{aligned}
f_{i}: G \times I & \rightarrow\{0,1\} \\
(g, j) & \mapsto f_{i}(g, j):= \begin{cases}1, & g(i)=j \text { bada } \\
0, & g(i) \neq j \text { bada } .\end{cases}
\end{aligned}
$$

Proposizioa frogatzeko, zenbatu dezagun bi eratara $f_{i}$ aplikazioaren 1eko kopurua.

Alde batetik, $g$ finkatzen baldin badugu, $g \in G$ simetrien talde bat izateagatik (ondo definituta egoteagatik), $g(i) \in I$ irudi bakar batekoa izango da. Orduan, $g$ finkaturik:

$$
\sum_{j \in 1} f_{i}(g, j)=1 \Rightarrow \sum_{g \in G}\left(\sum_{j \in 1} f_{i}(g, j)\right)=\sum_{g \in G} 1=|G| .
$$

Bestalde, $j \in I$ finkatzen baldin badugu, bi aukera daude:

$-j \notin O_{G}(i)$ bada, orduan $\nexists g \in G: g(i)=j$ den.

$-j \in O_{G}(i)$ bada, orduan $|\{g \in G \mid g(i)=j\}|={ }^{3}$. prop. $\left|\varepsilon_{G}(i)\right|$.

Beraz,

$$
\sum_{j \in 1}\left(\sum_{g \in G} f_{i}(g, j)\right)=\sum_{j \in O_{G}(i)}\left(\sum_{g \in G} f_{i}(g, j)\right)=\sum_{j \in O_{G}(i)}\left|\mathcal{E}_{G}(i)\right|=\left|O_{G}(i) \| \mathcal{E}_{G}(i)\right| .
$$


Ondorioz, $|G|=\left|O_{G}(i)\right|\left|\varepsilon_{G}(i)\right|, i \in I$ guztietarako.

5. Proposizioa. Izan bedi G I multzoaren simetrien taldea. Orduan,

$$
\sum_{g \in G}|F(g)|=\sum_{i \in I}\left|\mathcal{E}_{G}(i)\right|
$$

Froga. Kontsidera dezagun $f: G \times I \rightarrow\{0,1\}$ aplikazioa, non $f(g, i):=1$ baldin $g(i)=i$ bada, eta 0 kontrako kasuan. Behin eta berriro proposizioa frogatzeko, $f$ aplikazioaren leko kopurua bi eratara zenbatuko dugu. Alde batetik, $g \in G$ finkatzen baldin badugu:

$$
\{i \in I: g(i)=i\} \stackrel{3 . \text { def. }}{=} F(g) \Rightarrow \sum_{g \in G}\left(\sum_{i \in I} f(g, i)\right)=\sum_{g \in G}|F(g)| .
$$

Bestetik, $i \in I$ finkatzen baldin badugu:

$$
\{g \in G: g(i)=i\} \stackrel{2 \text {.def. }}{=} \mathcal{E}_{G}(i) \Rightarrow \sum_{i \in I}\left(\sum_{g \in G} f(g, i)\right)=\sum_{i \in I}\left|\mathcal{E}_{G}(i)\right|
$$

6. Proposizioa. Izan bedi $\left\{A_{1}, \ldots, A_{m}\right\}$ multzoen bilduma $I=\{1,2, \ldots, n\}$ multzoaren partiketa. $i \in I$ elementu bakoitzerako, izan bedi $a(i)$ zenbakia $i$ bere barnean duen partiketa horren azpimultzoaren kardinala. Orduan,

$$
\sum_{i \in I} \frac{1}{a(i)}=m, \text { hots, partiketaren azpimultzoen kopurua. }
$$

\section{Froga.}

$$
\sum_{i \in I} \frac{1}{a(i)}=\sum_{j=1}^{m} \sum_{i \in A_{j}} \frac{1}{a(i)}=\sum_{j=1}^{m}\left(\sum_{i \in A_{j}} \frac{1}{\left|A_{j}\right|}\right)=\sum_{j=1}^{m} 1=m .
$$

Emaitza lagungarri hauekin, enuntziatu eta froga dezagun Burnsideren lema (orbitak zenbatzeko Burnsideren lema, Cauchy-Frobeniusen lema edo orbitak zenbatzeko lema izenekin ere ezagun da). Emaitzaren jatorria ez da Burnsiderena - berak [13] liburuan aipatzen duenez - , 1887ko Frobeniusena baizik, [14]. 
7. Lema (Burnsideren lema). Izan bedi G I multzoaren simetrien taldea. Orduan,

$$
\mid\{G \text {-reriko } I \text {-ren orbitak }\}\left|=\frac{1}{|G|} \sum_{g \in G}\right| F(g) \mid \text {. }
$$

\section{Froga.}

$$
\begin{gathered}
\frac{1}{|G|} \sum_{g \in G}|F(g)| \stackrel{\text { 5.prop. }}{=} \frac{1}{|G|} \sum_{i \in I}\left|\mathcal{E}_{G}(i)\right| \stackrel{4 . p r o p . ~}{=} \frac{1}{|G|} \sum_{i \in I} \frac{|G|}{\left|O_{G}(i)\right|}=\sum_{i \in I} \frac{1}{\left|O_{G}(i)\right|}= \\
\stackrel{\substack{\text { 2.kor.+ } \\
\text { 6.prop. }}}{=} \mid\{G \text {-rekiko I-ren orbitak }\} \mid .
\end{gathered}
$$

Are gehiago, lema orokortu daiteke haztapen-funtzio baten menpe lan egiteko. Orokorrean, haztapen-funtzioek $\mathbb{Z}$ bere barnean duen eraztun batean har ditzakete balioak.

8. Lema (Burnsideren lema haztatua). Izan bedi $G$ I multzoaren simetrien taldea. Izan bedi $(\rho)$ I multzoan definitutako eta $G$-rekiko orbita guztietan konstante mantentzen den funtzioa ( $\rho$-ri haztapen-funtzioa deritzo), hau da, finkatuz $i \in I$,

$$
\rho(i)=\rho[g(i)], \quad g \in \text { G guztietarako } .
$$

Izan bedi $\theta$ orbita kopurua. Orbita bakoitzeko elementu bat hartuz, $\left(i_{1}, \ldots, i_{\theta}\right)$, orduan

$$
\sum_{j=1}^{\theta} \rho\left(i_{j}\right)=\frac{1}{|G|} \sum_{g \in G}\left(\sum_{i \in F(g)} \rho(i)\right)
$$

Haztapen-funtzioa $\rho(i)=1, \forall i \in I$ hartzen badugu, Burnsideren 7. lema dugu.

Froga. Aurreko lemaren analogoa da.

Behin orbita kopurua kalkula ditzakegunean, hurrengo pausoa izango da kalkulatzea zenbat eratan kolorezta daitezkeen $I$-ko elementuak $t \in \mathbb{N}$ kolore erabiliz.

4. Definizioa. Izan bitez $I=\left\{i_{1}, \ldots, i_{n}\right\}$ multzoa, eta $K=\left\{k_{1}, \ldots, k_{t}\right\}$ koloreen multzoa. I-ren kolorazioa I-tik K-ra doan aplikazioa da, eta kolorazio guztien multzoari $\mathrm{Col}_{t}(\mathrm{I})$ deituko diogu. 


$$
\begin{aligned}
\operatorname{Col}_{t}(I) & =\{\omega: I \rightarrow \text { K motako aplikazioak }\} \\
& =\{\text { I-ko elementuei koloreak esleitzeko erak }\} \\
& =\{t \text { sinboloz osatutako } n \text { luzerako zerrendak }\} .
\end{aligned}
$$

9. Proposizioa. Izan bitez I multzoa eta G I-ren simetrien talde bat. Orduan, G-ko elementuek Col $_{t}(I)$ multzoaren simetriak induzitzen dituzte, eta simetria hauek $\tilde{G}$ talde bat osatzen dute, $t>1$ denean $G$-ren isomorfoa dena.

Froga. Izan bedi $\tilde{g} \in \tilde{G}$ era honetan definitua:

$$
\begin{aligned}
\tilde{g}: \operatorname{Col}_{t}(I) & \rightarrow \operatorname{Col}_{t}(I) \\
\omega & \mapsto \tilde{g}(\omega):=\tilde{\omega}: I \rightarrow K \\
i & \mapsto \tilde{\omega}(i)=\left(\omega \circ g^{-1}\right)(i)
\end{aligned}
$$

Ikus dezagun $\tilde{G}=\{\tilde{g} \mid g \in G\}$ taldea dela konposizioarekiko $\left(\operatorname{Col}_{t}(I)\right.$ ren permutazio guztien azpitaldea). Alde batetik, $\forall \tilde{g}, \tilde{h} \in \tilde{G}, \tilde{g} \circ \tilde{h}=(\widetilde{g \circ h}) \in \tilde{G}$. Izan ere,

$$
(\widetilde{g \circ h})(\omega)=\omega \circ(g \circ h)^{-1}=\omega \circ\left(h^{-1} \circ g^{-1}\right)=\left(\omega \circ h^{-1}\right) \circ g^{-1}=\tilde{h}(\omega) \circ g^{-1}=(\tilde{g} \circ \tilde{h})(\omega) .
$$

Bestalde,

$$
\tilde{g} \circ \widetilde{g^{-1}}=\widetilde{g \circ g^{-1}}=\tilde{1}=1_{C o l_{t}(I)} \Rightarrow \tilde{g}^{-1}=\widetilde{g^{-1}} \in \tilde{G} .
$$

Gainera, $\tilde{g}$ bijektiboa denez, $\tilde{G} \operatorname{Col}_{t}(I)$-ren permutazioen azpimultzoa da, $\tilde{g} \in S_{\mathrm{Col}_{t}}(I)$. Orain, $\tilde{G}$ taldea dela jakinda, izan bedi aplikazio hau:

$$
\begin{aligned}
\phi: \quad G & \rightarrow \tilde{G} \\
g & \mapsto \tilde{g} .
\end{aligned}
$$

Orduan, (3) adierazpenagatik, $\phi$ homomorfismoa da. Gainera, $\phi$ ere bijektiboa da. Argi dago surjektiboa dela $\phi$-ren definizioaz. Azkenik, froga dezagun injektiboa ere badela. Horretarako, ikus dezagun lehenengoz honako propietate hau:

$$
t>1 \text { denean, } \quad \tilde{g}=1_{\mathrm{Col}_{t}}(I) \Rightarrow g=1_{I} .
$$

Absurdura eramanez, demagun $t>1$ dela eta $\tilde{g}=1_{\text {Col }_{t}}(I)$ baina $g \neq 1_{I}$. Orduan, $\exists i, j \in I, i \neq j$, non $g(i)=j$ den. Defini dezagun $\omega \in \operatorname{Col}_{t}(I)$ kolorazio berezi hau: 


$$
\left\{\begin{array}{c}
\omega(i)=k_{1}, \\
\omega(j)=k_{2}, \quad j \neq i \text { denean }
\end{array}\right.
$$

non $k_{1} \neq k_{2}$ bi kolore ezberdin diren. Orduan,

$$
\tilde{g}(\omega)(j)=\left(\omega \circ g^{-1}\right)(j)=\omega\left(g^{-1}(j)\right)=\omega(i)=k_{1} \neq k_{2}=\omega(j) .
$$

Eta kontraesana lortu dugu, $\tilde{g}=1_{\mathrm{Clt}_{t}}(I)$ baita. Amaitzeko, froga dezagun $\phi(g)=\phi(h) \Rightarrow g=h$. Izan ere,

$$
\tilde{g}=\tilde{h} \Rightarrow \overline{g \circ h^{-1}}=\tilde{1}=1_{C o l_{t}(I)}
$$

Eta $t>1$ denez, frogatu berri dugun propietateagatik: $g \circ h^{-1}=1_{I}$, hots, $g=h$.

Hemendik aurrera, $t>1$ baino ez da gure interesekoa izango. Gainera, ez ditugu $G$ eta $\tilde{G}$ desberdinduko, eta $G I$-ren eta $\operatorname{Col}_{t}(I)$-ren simetrien talde bat izango da. Ondorioz, $G \mathrm{Col}_{t}(I)$-ren simetrien talde bat izateagatik, $\mathrm{Col}_{t}(I)$-ren partiketa bat sortuko da (hau da, orbitak sortuko dira), eta, ondorioz, Burnsideren lema garatu dezakegu egoera honetara.

5. Definizioa. Izan bedi $\omega_{1}, \omega_{2} \in \operatorname{Col}_{t}(I)$ bi kolorazio ezberdin. Beraz, $\omega_{1}$ eta $\omega_{2} G$-ren gaineko kolorazio baliokideak izango dira baldin eta

$$
\exists g \in G: g\left(\omega_{1}\right)=\omega_{2} .
$$

Beraz, $G$-ren gaineko kolorazio ez-baliokideen kopurua $G$-k $\operatorname{Col}_{t}(I)$-n zehazten dituen orbiten kopurua izango da; eta, azken hau kalkulatzeko, Burnsideren lema daukagu.

10. Lema (Burnsideren lema kolorazioetarako). Izan bitez $n$ elementuko I multzoa, G simetrien taldea eta t koloreko K multzoa. Orduan,

$$
\begin{gathered}
\left|\left\{\begin{array}{c}
G \text {-ren gainekoCol } C_{t}(I)-k o \\
\text { kolorazioez-baliokideak }
\end{array}\right\}\right|=\frac{1}{|G|} \sum_{g \in G}\left|\left\{\begin{array}{c}
\text { g-renbitartez finko gelditzen } \\
\text { diren } \text { Col }_{t}(I) \text {-ko kolorazioak }
\end{array}\right\}\right|= \\
=\frac{1}{|G|} \sum_{g \in G} t^{\mid\{\text {-renzikloak }\} \mid}=\frac{1}{|G|} \sum_{i=1}^{|l|}\left|\left\{\begin{array}{c}
i \text { zikloko } \\
G \text {-kozimetriak }
\end{array}\right\}\right| t^{i} .
\end{gathered}
$$

Froga. Lehenengo berdintza frogatzeko, Burnsideren 7. lema erabil daiteke zuzenean, $I$-ren ordez $\operatorname{Col}_{t}(I)$ erabiliz. Bigarren berdintza $G$-ko si- 
Lauki-sareko patroiak kalkulatzea, Pólyaren teoriaren eskutik

metriak ziklo disjuntuen biderkadura gisa adieraztean lortutako emaitza da. Izan ere, $g$-ren orbitak beren zikloetako elementuak dira, eta, sortutako orbita bakoitzean, elementuen kolorea bera da. Hirugarren berdintza notazioa baino ez da.

Lehen bezala, orokortu daiteke Burnsideren lema kolorazioetarako haztapen-funtzio baten menpe.

11. Lema (Burnsideren lema haztatua kolorazioetarako). Izan bitez $n$ elementuko I multzoa, $G$ simetrien taldea eta $t$ koloreko $K$ multzoa. Izan bedi $\rho \operatorname{Col}_{t}(I)-n$ definitutako eta $G$-rekiko orbita guztietan konstante mantentzen den funtzioa; hau da, finkatuz $\omega \in \operatorname{Col}_{t}(I)$,

$$
\rho(\omega)=\rho[g(\omega)], \forall g \in G .
$$

Demagun $\theta$ orbita daudela eta $F(g) g-k$ finkatzen dituen kolorazioak direla. Orduan, orbita bakoitzeko elementu bat hartuz $\left(\omega_{1}, \omega_{2}, \ldots, \omega_{\theta}\right)$,

$$
\sum_{j=1}^{\theta} \rho\left(\omega_{j}\right)=\frac{1}{|G|} \sum_{g \in G}\left(\sum_{\omega \in F(g)} \rho(\omega)\right) .
$$

Ohartu $\rho=1$ denean, Burnsideren kolorazioetarako 10. lema dugula.

Froga. Burnsideren 8. lema haztatuaren aplikazioa da.

Azkenengo emaitza honi esker, lan honen helburuetako bat egiteko gai izango gara: $t$ koloreko patroi ez-baliokideen kopurua kalkulatzea (gogora dezagun lan honen bigarren helburua dela koloreen maiztasunak jakinik patroi ez-baliokideen kopurua lortzeko bidea ematea). Horretarako, zenbait definizio berri beharko ditugu.

6. Definizioa. Izan bedi $\omega \in \operatorname{Col}_{t}(I)$ kolorazioa. $\omega$ kolorazioari t aldagaiko honako monomio hau esleituko diogu:

$$
x_{1}^{n_{1}(\omega)} x_{2}^{n_{2}(\omega)} \cdots x_{t^{n^{\prime}}}^{n^{(\omega)}} .
$$

non $n_{j}(\omega)$ berretzaile bakoitza baita $\omega$ kolorazioan $j$ kolorea jasoko duten I-ko elementuen kopurua, hots, $j$ kolorearen maiztasuna $n_{j}(\omega)$ den, $j=1, \ldots, t$. Beraz, Col $(I)$-ko elementuak $t$ sinboloz osatutako $n$ luzerako zerrendak direnez,

$$
n_{1}(\omega)+n_{2}(\omega)+\cdots+n_{t}(\omega)=n, \omega \in \text { Col }_{t}(I) \text { guztietarako } .
$$

Har dezagun $\Omega$ kolorazioen azpimultzoa, $\Omega \subseteq$ Col$_{t}(I)$. Orduan, defini dezagun $\Omega$ kolorazio multzoaren inbentarioa honako funtzio sortzaile honen bidez: 


$$
\mathcal{I}_{\Omega}\left(x_{1}, x_{2}, \ldots, x_{t}\right)=\sum_{\omega \in \Omega} x_{1}^{n_{1}(\omega)} x_{2}^{n_{2}(\omega)} \cdots x_{t}^{n_{t}(\omega)} .
$$

Beraz, $\Omega$ aukera ez-baliokideen multzoa baldin bada, inbentarioaren koefizienteek gure bigarren helburuari erantzuten diote. Baina nola lortzen dugu inbentarioa $\Omega$ ezagutu gabe?

12. Lema (Atalkako kolorazioen inbentarioa). Izan bedi I multzo bat, eta har dezagun I-ren s tamainako partiketa: $A_{1}, \ldots, A_{s}$, non atal bakoitzeko elementu guztiei kolore berdina ezarri nahi diogun. Aurreko baldintza betetzen duten t koloreko I-ren kolorazio guztien multzoari $\Omega$ inbentarioa deituko diogu. Orduan, $j=1, \ldots$, s bakoitzerako, $m_{j}=\left|A_{j}\right|$ definituz, zera betetzen da:

$$
\mathcal{I}_{\Omega}\left(x_{1}, x_{2}, \ldots, x_{t}\right)=\left(x_{1}^{m_{1}}+\cdots+x_{t}^{m_{1}}\right) \cdot\left(x_{1}^{m_{2}}+\cdots+x_{t}^{m_{2}}\right) \cdot \cdots \cdot\left(x_{1}^{m_{s}}+\cdots+x_{t}^{m_{s}}\right) .
$$

Froga. Lema indukzioz frogatuko dugu. Nabaria denez, $t=1$ eta $s=1$ denean, kolore batez koloreztatzen ari gara $I$ multzo osoa. Beraz, $\mathcal{I}_{\Omega}\left(x_{1}\right)=x_{1}{ }^{m_{1}}=x_{1}{ }^{|I|}$. Era berean gertatuko litzateke $t=1$ denean, $s \in \mathbb{N}$ guztietarako. Azter dezagun $t \geq 2$ eta $s=2$ den kasua $t$-rekiko indukzioz.

$-t=2$ denean, $\Omega$-k 4 kolorazio izango ditu: $A_{i}$ bloke bakoitzerako $x_{j}$ kolorea izatea, $i, j=1,2$. Beraz, kolorazio bakoitzaren monomioen esleipena hau da:

$$
x_{1}^{m_{1}} x_{1}^{m_{2}}, x_{1}^{m_{1}} x_{2}^{m_{2}}, x_{2}^{m_{1}} x_{1}^{m_{2}}, x_{2}^{m_{1}} x_{2}^{m_{2}} .
$$

Eta batuz,

$$
\mathcal{I}_{\Omega}\left(x_{1}, x_{2}\right)=x_{1}^{m_{1}} x_{1}^{m_{2}}+x_{1}^{m_{1}} x_{2}^{m_{2}}+x_{2}^{m_{1}} x_{1}^{m_{2}}+x_{2}^{m_{1}} x_{2}^{m_{2}}=\left(x_{1}^{m_{1}}+x_{2}^{m_{1}}\right) \cdot\left(x_{1}^{m_{2}}+x_{2}^{m_{2}}\right) .
$$

- Suposa dezagun $t-1$ kasurako betetzen dela, hau da,

$$
\mathcal{I}_{\Omega}\left(x_{1}, \ldots, x_{t-1}\right)=\left(x_{1}^{m_{1}}+\cdots+x_{t-1}^{m_{1}}\right) \cdot\left(x_{1}^{m_{2}}+\cdots+x_{t-1}^{m_{2}}\right) .
$$

Beraz, $t$ kolore izanda, $x_{t}$ kolorearen aukera gehituko genioke. Beraz, $x_{t}$ aldagaia parte duten monomioak gehituko genizkioke; hau da,

$$
x_{t}^{m_{1}} x_{1}^{m_{2}}, x_{t}^{m_{1}} x_{2}^{m_{2}}, \cdots, x_{t}^{m_{1}} x_{t-1}^{m_{2}}, x_{1}^{m_{1}} x_{t}^{m_{2}}, x_{2}^{m_{1}} x_{t}^{m_{2}}, \cdots, x_{t-1}^{m_{1}} x_{t}^{m_{2}}, x_{t}^{m_{1}} x_{t}^{m_{2}}
$$

monomioak $\mathcal{I}_{\Omega}\left(x_{1}, \ldots, x_{t-1}\right)$ inbentarioarekin batuko genituzke. $x_{t}$ aldagaia parte duten monomioen batura kontsideratuz,

$$
\left(x_{1}^{m_{2}}+x_{2}^{m_{2}}+\cdots+x_{t-1}^{m_{2}}\right) x_{t}^{m_{1}}+\left(x_{1}^{m_{1}}+x_{2}^{m_{1}}+\cdots+x_{t-1}^{m_{1}}\right) x_{t}^{m_{2}}+x_{t}^{m_{1}} x_{t}^{m_{2}} .
$$




$$
\begin{aligned}
& \operatorname{Beraz}, \mathcal{I}_{\Omega}\left(x_{1}, \ldots, x_{t}\right)= \\
= & \mathcal{I}_{\Omega}\left(x_{1}, \ldots, x_{t-1}\right)+\left(x_{1}^{m_{2}}+x_{2}^{m_{2}}+\cdots+x_{t-1}^{m_{2}}\right) x_{t}^{m_{1}}+\left(x_{1}^{m_{1}}+x_{2}^{m_{1}}+\cdots+x_{t-1}^{m_{1}}\right) x_{t}^{m_{2}}+x_{t}^{m_{1}} x_{t}^{m_{2}}= \\
= & \left(x_{1}^{m_{2}}+\cdots+x_{t-1}^{m_{2}}\right)\left[\left(x_{1}^{m_{1}}+\cdots+x_{t-1}^{m_{1}}\right)+x_{t}^{m_{1}}\right]+\left[\left(x_{1}^{m_{1}}+\cdots+x_{t-1}^{m_{1}}\right) x_{t}^{m_{1}}\right] x_{t}^{m_{2}}= \\
= & \left(x_{1}^{m_{1}}+\cdots+x_{t}^{m_{1}}\right) \cdot\left(x_{1}^{m_{2}}+\cdots+x_{t}^{m_{2}}\right) .
\end{aligned}
$$

Prozedura analogo batean froga daiteke $s>2$ denean.

7. Definizioa. Izan bitez $G$ I-ren gaineko simetrien taldea, eta $g \in G$. Defini dezagun $\Omega_{g}$ g-ren bitartez finko gelditzen diren kolorazioen multzoa:

$$
\Omega_{g}=\left\{\omega \in \operatorname{Col}_{t}(I) \mid g(\omega)=\omega\right\}=F(g) .
$$

Beraz, $I_{\Omega_{g}}, \Omega_{g}$ multzoaren inbentarioa ezagutu nahiko dugu.

13. Proposizioa (g simetriak finkatutako kolorazioen inbentarioa). Izan bedi $g$ I-ren gaineko simetria. Orduan, $g$-k finkatzen dituen t koloreko kolorazioen inbentarioa

$$
\mathcal{I}_{\Omega_{g}}\left(x_{1}, \ldots, x_{t}\right)=y_{1}^{c_{1}(g)} y_{2}^{c_{2}(g)} \cdots y_{n}^{c_{n}(g)}
$$

da, non $j=1, \ldots, n$ guztietarako $c_{j}(g)$ baita $g$ simetriaren $j$-ziklo kopurua eta $y_{j}=x j+\cdots+x_{t}^{j}$ den.

Froga. Demagun $g$ permutazioa idaztean $I s$ ziklotan banatzen dela: $\left\{A_{1}, \ldots, A_{s}\right\}$. Orduan, $\Omega_{g}$-ko kolorazioak $A_{i}$ ziklo bakoitzari kolore bat ezartzen dio: $i=1, \ldots, s$. Ondorioz, 12. lema erabiliz,

$$
\mathcal{I}_{\Omega_{g}}\left(x_{1}, \ldots, x_{t}\right)=\prod_{j=1}^{s}\left(x_{1}^{m_{j}}+\cdots+x_{t}^{m_{j}}\right),
$$

non $m_{j} A_{j}$ zikloaren luzera den.

Notazioaren honako aldaketa hau eginez,

$$
y_{m_{j}}=x_{1}^{m_{j}}+x_{2}^{m_{j}}+\cdots+x_{t}^{m_{j}} \text {, orduan, } \mathcal{I}_{\Omega_{g}}\left(x_{1}, \ldots, x_{t}\right)=\prod_{j=1}^{s} y_{m_{j}} .
$$

Ziklo bakoitzak bere luzera izango duenez, sailka ditzagun luzera bereko zikloak batera egon daitezen. Izan bedi $c_{j}(g) g$ simetriaren $j$ luzerako 
zikloen kopurua: $j=1, \ldots, n$. Beraz, $y_{j}$ aldagaiak $c_{j}(g)$ alditan agertuko denez,

$$
\mathcal{I}_{\Omega_{g}}\left(x_{1}, \ldots, x_{t}\right)=y_{1}^{c_{1}(g)} y_{2}^{c_{2}(g)} \cdots y_{n}^{c_{n}(g)} .
$$

8. Definizioa. Izan bitez I n elementuko multzoa eta G I-ren simetrien taldea.g G-ko simetria bakoitzari honako monomio hau esleituko diogu:

$$
y_{1}^{c_{1}(g)} y_{2}^{c_{2}(g)} \cdots y_{n}^{c_{n}(g)}
$$

non $c_{j}(g)$ berretzaile bakoitza $g$ simetriaren $j$-zikloen kopurua den, $j=1, \ldots, n$ (oraingoz, $y_{1}, \ldots, y_{n}$ aldagai berrien izenak izango dira, eta ez daukate esanahirik). Orduan, $\sum_{j=1}^{n} j \cdot c_{j}(g)=n$. Beraz, defini dezagun $G$ simetrien taldearen zikloen funtzio adierazlea (edo simetrien taldearen adierazlea):

$$
\mathcal{J}_{G}\left(y_{1}, \ldots, y_{n}\right)=\frac{1}{|G|} \sum_{g \in G} y_{1}^{c_{1}(g)} y_{2}^{c_{2}(g)} \cdots y_{n}^{c_{n}(g)}
$$

Jarraian, Pólyaren teorema edo Redfield-Pólya-ren teorema aurkeztuko dugu, Burnsideren lemaren orokorpena dena. Lehenengoz John Howard Redfieldek argitaratu zuen 1927an. Baina 1937an George Pólyak aurkitu zuen berriz era askean, eta berak ospea eman zion hainbeste zenbatzeko problematan aplikatu ostean.

14. Teorema (Pólyaren teorema kolorazioetarako). Izan bitez I $n$ elementuko multzoa; $t$, koloreak eta hauekin sor daitezkeen Col $(I)$ kolorazioen multzoa; eta $G$, I-ren zein $\mathrm{Col}_{t}(I)$-ren gaineko simetrien taldea. Izan bedi $\Omega$ multzoa Col $_{t}(I)$-ren gaineko $G$-ren bidezko orbita bakoitzean kolorazio bakar bat kontuan hartzen duena. Orduan, $\Omega$ G-ren gaineko $\mathrm{Col}_{t}(I)$-ko kolorazio ez-baliokideen multzoaren inbentarioa era honetan kalkula daiteke:

$$
\mathcal{I}_{\Omega}\left(x_{1}, \ldots, x_{t}\right)=\mathcal{J}_{G}\left(y_{1}, \ldots, y_{n}\right),
$$

non $y_{i}=x_{1}^{i}+x_{2}^{i}+\cdots+x_{t}^{i}$ den, $i=1, \ldots, n$ guztietarako.

Froga. Definizioz, $\mathcal{I}_{\Omega}\left(x_{1}, \ldots, x_{t}\right)=\sum_{\omega \in \Omega} x_{1}^{n_{1}(\omega)} \cdots x_{t}^{n_{t}(\omega)}$, non $n_{j}(\omega)$ baita $\omega$ kolorazioan $j$ kolorearen maiztasuna. Defini dezagun $\rho$ haztapen-funtzioa $\operatorname{Col}_{t}(I)$-ren gainean: 


$$
\begin{aligned}
\rho: \operatorname{Col}_{t}(I) & \rightarrow \mathbb{Z}\left[x_{1}, \ldots, x_{t}\right] \\
\omega & \mapsto \rho(\omega)=x_{1}^{n_{1}(\omega)} \cdots x_{t}^{n_{t}(\omega)}
\end{aligned}
$$

Nabaria denez, edozein $g \in G$ hartuz, $n_{j}(g(\omega))=n_{j}(\omega), j=1, \ldots, n$; hots, simetriak ez du kolorazioen kolore kopurua aldatzen. Beraz, $\rho(g(\omega))=\rho(\omega)$. Orduan, $\rho$ funtzioa konstantea da $G$-ko orbiten gainean. Burnsideren kolorazioetarako 11. lema haztatuagatik,

$$
\begin{aligned}
& \mathcal{I}_{\Omega}\left(x_{1}, \ldots, x_{t}\right) \stackrel{\text { 6.def. }}{=} \sum_{\omega \in \Omega} \rho(\omega) \stackrel{11 . \text { lema }}{=} \frac{1}{|G|} \sum_{g \in G}\left(\sum_{\omega \in F(g)} \rho(\omega)\right)^{7 . \text { def. }}=\frac{1}{|G|} \sum_{g \in G} \mathcal{I}_{\Omega_{g}}= \\
& \begin{array}{l}
\text { 13.prop. }|G| \\
\mid G \in G
\end{array} y^{c_{1}(g)} \cdots y_{n}^{c_{n}(g)} \text { 8. }{ }_{\text {8def. }} \mathcal{J}_{G}\left(y_{1}, \ldots, y_{n}\right) .
\end{aligned}
$$

Orain, bai: $\Omega$ ezagutu gabe, jakin dezakegu zenbat lauki-sare ez-baliokide diren $t$ koloreen maiztasunak ezagututa.

\section{KLEIN TALDEAREKIKO MATRIZE EZ-BALIOKIDEEN KOPURUA}

Kasu honetan, gure elementuak $r \times s$ matrizearen osagaiak dira. $I=\left\{a_{i j}: i=1, \ldots, r, j=1, \ldots, s\right\}, r, s \in \mathbb{N}$. Gogora dezagun sarrerako aparkaleku txartelen problema. Txartela edozein posiziotan sartzea posible denez, zirrikitua $r$ laukiko luzerakoa izanik, lau aukera ditugu: identitatea, islapena, $\pi$ angeluko biraketa eta azken bi hauen konbinaketa egitea. Zehazten ari garena $G$ simetrien taldea da. Izan ere, simetriak matrizearen osagaien multzoa finko utzi behar duenez, $G$ taldea hurrengo elementuez osatuta dago:

$$
G=\left\{1_{G}, \sigma_{2}, e_{1}, e_{3}\right\},
$$

non:

$1_{G}$ baita $G$ taldearen elementu neutroa, hau da, matrizearen osagai guztiak finko uzten dituen simetria bakarra;

$\sigma_{2}$, matrizearen $\pi$ angeluko biraketa;

$e_{1}$, matrizearen ardatz bertikalarekiko islapena; eta

$e_{3}$, matrizearen ardatz horizontalarekiko islapena, hots, $e_{3}=\sigma_{2} \circ e_{1}$.

Adibidez, $2 \times 3$ matrize batean $G$ taldeak 2 . irudian adierazten den bezala eragiten du. 


$$
\begin{gathered}
\left(\begin{array}{lll}
a_{11} & a_{12} & a_{13} \\
a_{21} & a_{22} & a_{23}
\end{array}\right) \\
1_{G}=\left(\begin{array}{lll}
a_{23} & a_{22} & a_{21} \\
a_{13} & a_{12} & a_{11}
\end{array}\right) \\
\sigma_{2} \\
e_{1} \\
e_{3}
\end{gathered}
$$

2. irudia. $2 \times 3$ matrizearen gaineko simetriak.

Talde hau, bereziki, $D_{4}$ talde diedrikoaren azpitalde berezia da, Klein-en taldea izenekoa.

\subsection{Orbiten kalkulua}

Taldeko simetriekin errazago lan egiteko, adieraz ditzagun $G$-ko elementuak ziklo disjuntuen biderkadura gisa (identitatea izan ezik). Horretarako, kontuan izan behar dugu $r$ eta $s$ balioen bikoitasuna, kasu guztiak ondo adierazteko (ikusi 3. irudia).

$$
\begin{aligned}
& \left(\begin{array}{cccc}
a_{11} & a_{12} & a_{13} & a_{14} \\
a_{21} & a_{22} & a_{23} & a_{24}
\end{array}\right) \quad\left(\begin{array}{ll}
a_{11} & a_{12} \\
a_{21} & a_{22} \\
a_{31} & a_{32}
\end{array}\right) \quad\left(\begin{array}{lll}
a_{11} & a_{12} & a_{13} \\
a_{21} & a_{22} & a_{23}
\end{array}\right) \quad\left(\begin{array}{lllll}
a_{11} & a_{12} & a_{13} & a_{14} & a_{15} \\
a_{21} & a_{22} & a_{23} & a_{24} & a_{25} \\
a_{31} & a_{32} & a_{33} & a_{34} & a_{35}
\end{array}\right) \\
& \begin{array}{llll}
2 \times 4 & 3 \times 2 & 2 \times 3 & 3 \times 5
\end{array} \\
& \text { (1. kasua) (2. kasua) (3. kasua) (4. kasua) }
\end{aligned}
$$

3. irudia. Bikoitasunaren araberako matrize motak.

Beraz, simetria guztietan osagai bakoitza behin agertuko da ziklo disjuntuen biderkaduran. Osagai finko baten orbita zein den jakiteko, nahikoa da simetria bakoitzerako ziklo disjuntuen biderkaduran osagaia bilatu eta ziklo horren barneko elementu guztiak hartzea. Haien bildurak osagaiaren orbita osatzen du.

Burnsideren 7. lema erabiliz, zenbatu dezagun $G$-rekiko $I$-ren orbita desberdin kopurua, lerro eta zutabe kopuruaren arabera:

$$
\mid\{G \text {-rekiko } I \text {-ren orbitak }\} \mid=\frac{1}{4}\left(\left|F\left(1_{G}\right)\right|+\left|F\left(\sigma_{2}\right)\right|+\left|F\left(e_{1}\right)\right|+\left|F\left(e_{3}\right)\right|\right) .
$$

- 1. kasua: $r$ eta $s$ bikoitiak direnean, $r=2 n$ eta $s=2 m$.

Kasu honetan, simetria guztiak, identitatea izan ezik, transposizio disjuntuen biderkaduraz osatuta daude; hau da, ez daukate puntu finkorik. Beraz,

$$
\mid\{G \text {-rekiko } I \text {-ren orbitak }\} \mid=\frac{r s}{4} .
$$


- 2. kasua: $r$ bakoitia eta $s$ bikoitia denean, $r=2 n+1$ eta $s=2 m$.

Egoera honetan, ardatz horizontalarekiko islapenak erdiko errenkada finko uzten du, $e_{3}$ simetriak $s$ osagai finko utziz. Hortaz,

$$
\mid\{G \text {-rekiko } I \text {-ren orbitak }\} \mid=\frac{r s+s}{4} .
$$

- 3. kasua: $r$ bikoitia eta $s$ bakoitia denean, $r=2 n$ eta $s=2 m+1$. Orain, $e_{1}$ simetriaren $r$ puntu finkoak kontuan hartuz,

$$
\mid\{G \text {-rekiko } I \text {-ren orbitak }\} \mid=\frac{r s+r}{4} \text {. }
$$

- 4. kasua: $r$ eta $s$ bakoitiak direnean, $r=2 n+1$ eta $s=2 m+1$. Azkenengo kasu honetan, islapen bakoitzak zutabe edo errenkada bat finkatuta uzteaz gain, $\sigma_{2}$ biraketak ere osagai zentrala uzten du finko: $a_{(n+1)(m+1)}$. Beraz,

$$
\mid\{G \text {-rekiko } I \text {-ren orbitak }\} \mid=\frac{r s+r+s+1}{4} .
$$

\section{2. $r \times s$ matrizeen kolorazio ez-baliokideen kopurua}

Orain, kontsidera ditzagun osagai bakoitzak har ditzakeen $K$ multzoko balioak. Horrela, $t$ kolorez osatutako matrizeen kolorazioen multzoa sor dezakegu: $\operatorname{Col}_{t}(I)$. Gainera, $G I$-ren simetrien talde bezala ikusteaz gain, $\operatorname{Col}_{t}(I)$-ren simetrien taldetzat har daiteke. Honi esker, $G$-ren gaineko $\mathrm{Col}_{t}(I)$-ko kolorazio ez-baliokideen kopurua kalkulatuko dugu, Burnsideren kolorazioetarako 10. lema erabiliz:

$$
a(r, s ; t)=\left|\left\{\begin{array}{l}
G \text {-rengaineko } C_{t}(I)-\mathrm{ko} \\
\text { kolorazioez-baliokideak }
\end{array}\right\}\right|=\frac{1}{4} \sum_{i=1}^{r s}\left|\left\{\begin{array}{c}
i \text { zikloko } \\
G \text {-ko simetriak }
\end{array}\right\}\right| t^{i} .
$$

- 1. kasua: $r$ eta $s$ bikoitiak direnean, $r=2 n$ eta $s=2 m$.

- $1_{G}$ aplikazioak kolorazio guztiak finko uzten ditu. Beraz, osagai bakoitzerako balio bat emateko aukera izango du: $t^{r s}$.

- $e_{1}$ eta $e_{3}$ islapenak puntu finkorik ez duten transposizio disjuntuen biderkadura gisa adierazten direnez, $r s / 2$ zikloz osatuta daude: $t^{r s / 2}$.

- $\sigma_{2}$ biraketak osagaiak binaka erlazionatzen ditu. Beraz, $r s / 2$ ziklo disjuntuz osatuta dago: $t^{r s / 2}$. 
- 2. kasua: $r$ bakoitia eta $s$ bikoitia direnean, $r=2 n+1$ eta $s=2 m$.

- $1_{G}$ aplikazioak kolorazio guztiak finko uzten ditu: $t^{r s}$.

- $e_{1}$ eta $\sigma_{2}$ aplikazioak puntu finkorik ez duten transposizio disjuntuen biderkadura gisa adierazten direnez, $r s / 2$ zikloz osatuta daude: $t^{r / 2}$.

- $e_{3}$ islapenak erdiko errenkadako osagai guztiak finko uzten ditu $(s)$, eta beste osagai guztiak $(r s-s)$ transposizio disjuntuetan banatzen ditu. Beraz, $s+\frac{r s-s}{2}=\frac{r s+s}{2}$ zikloz osatuta dago: $t^{\frac{r s+s}{2}}$.

-3. kasua: $r$ bikoitia eta $s$ bakoitia direnean, $r=2 n$ eta $s=2 m+1$. Matrizea aurrekoaren iraulia denez, $r$ eta $s$-ren paperak trukatu egiten dira.

- 4. kasua: $r$ eta $s$ bakoitiak direnean, $r=2 n+1$ eta $s=2 m+1$.

- $1_{G}$ aplikazioak kolorazio guztiak finko uzten ditu: $t^{r s}$.

- $e_{1}$ islapenak erdiko zutabeko osagai guztiak finko uzten ditu $(r)$, eta beste osagai guztiak $(r s-r)$ transposizio disjuntuetan banatzen ditu. Beraz, $r+\frac{r s-r}{2}=\frac{r s+r}{2}$ zikloz osatuta dago: $t^{\frac{r s+r}{2}}$.

- $e_{3}$ islapenak erdiko errenkadako osagai guztiak finko uzten ditu $(s)$, eta beste osagai guztiak $(r s-s)$ transposizio disjuntuetan banatzen ditu. Beraz, $s+\frac{r s-s}{2}=\frac{r s+s}{2}$ zikloz osatuta dago: $t^{\frac{r s+s}{2}}$.

- $\sigma_{2}$ biraketak osagai bakar bat finko uzten du $\left(a_{(n+1)(m+1)}\right.$, hain zuzen ere), eta beste osagai guztiak ( $r s-1)$ transposizio disjuntuetan banatzen ditu. Beraz, $1+\frac{r s-1}{2}=\frac{r s+1}{2}$ zikloz osatuta dago: $t^{\frac{r s+1}{2}}$.

Laburbilduz, (4) adierazpenean, lehenengo helburuaren formulak ditugu.

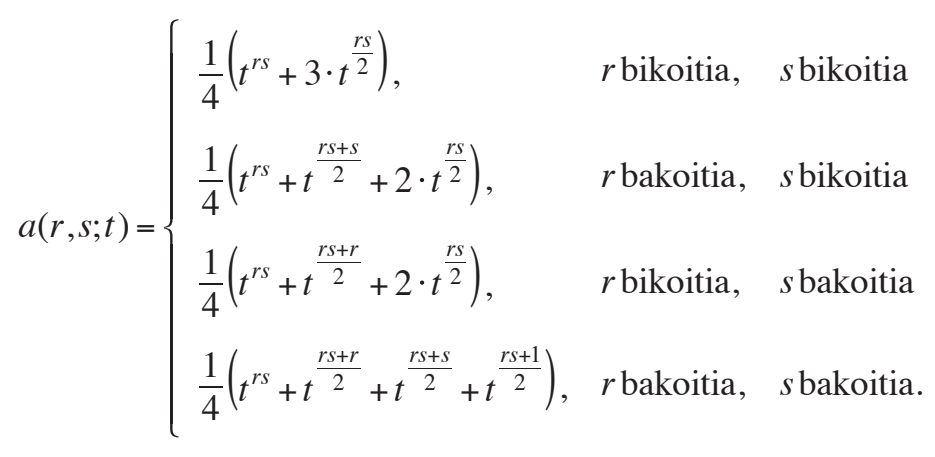


Matrize bitarren kasuan, 0 eta 1 elementuez osatutako matrizeak, edo - gauza bera dena $-t=2$ denean, matrize ez-baliokideen kopurua bat dator [2] artikuluan lortutako emaitzekin, hots, (1) adierazpenekin. Esate baterako, 4. irudian Klein taldearekiko $2 \times 2$ matrize bitar ez-baliokideak ikusten dira. 1. taulan OEIS entziklopedian agertzen diren segidak kontsulta daitezke (ikusi [3]); taularen beheko segidak lan honen ondorio dira.
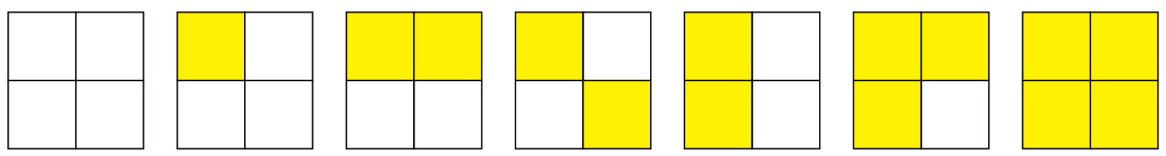

4. irudia. $a(2,2 ; 2)=7$ aukera Klein-ekiko $2 \times 2$ matrize bitarrak adierazteko.

1. taula. $a(r, s ; t)$ segidak OEISn

\begin{tabular}{lrllr}
\hline \multicolumn{1}{c}{$(r, s)$} & \multicolumn{1}{c}{$t$} & OEIS kodea & \multicolumn{1}{c}{ Egileak, urtea } & Ref. \\
\hline$(1, s)$ & 2 & A005418 & N. J. A. Sloane, R. K. Guy & $(1)$ \\
$(2: 10, s)$ & 2 & A225826:34 & Y. Yurramendi, 2013 & $(1)$ \\
$(r, s)$ & 2 & A225910 & Y. Yurramendi, 2013 & $(1)$ \\
$(r, s)$ & 3 & A283432 & M. Merino, I. Unanue, Y. Yurramendi, 2017 & $(4)$ \\
$(r, s)$ & 4 & A283433 & M. Merino, I. Unanue, Y. Yurramendi, 2017 & $(4)$ \\
$(r, s)$ & 5 & A283434 & M. Merino, I. Unanue, Y. Yurramendi, 2017 & $(4)$ \\
$(r, s)$ & 6 & A286893 & M. Merino, I. Unanue, Y. Yurramendi, 2017 & $(4)$ \\
$(r, s)$ & 7 & A286895 & M. Merino, I. Unanue, Y. Yurramendi, 2017 & $(4)$ \\
$(r, s)$ & 8 & A286919 & M. Merino, I. Unanue, Y. Yurramendi, 2017 & $(4)$ \\
$(r, s)$ & 9 & A286920 & M. Merino, I. Unanue, Y. Yurramendi, 2017 & $(4)$ \\
$(r, s)$ & 10 & A286921 & M. Merino, I. Unanue, Y. Yurramendi, 2017 & $(4)$ \\
\hline
\end{tabular}

\section{3. $r \times s$ matrizeen kolorazioetarako inbentarioa}

Azkenik, kontsidera dezagun $\Omega G$-ren gaineko $\operatorname{Col}_{t}(I)$-ko kolorazio ezbaliokideen multzoa. Gure bigarren helburua da $G$-ren gaineko kolorazio ez-baliokideen kopurua kalkulatzea $t$ kolore bakoitzerako matrizean zenbat aldiz agertzen den jakinik. Teorian ikusi izan dugu $\Omega$-ren inbentarioaren, $\mathcal{I}_{\Omega}\left(x_{1}, \ldots, x_{t}\right)$-ren, koefizienteek emaitza zuzenean ematen digutela, baina $\mathcal{I}_{\Omega}\left(x_{1}, \ldots, x_{t}\right)$ kalkulatzea oso zaila izan daiteke. Zorionez, Pólyaren kolorazioetarako 14. teoremak bide zuzen bat ematen digu inbentarioa kalkulatzeko:

$$
\mathcal{I}_{\Omega}\left(x_{1}, \ldots, x_{t}\right)=\mathcal{J}_{G}\left(y_{1}, \ldots, y_{r s}\right),
$$

non $\mathcal{J}_{G}$ baita $G$ simetrien taldearen adierazlea, eta $y^{i}=x_{1}^{i}+\cdots+x_{t}^{i}$ ordezkapena egin behar den: $i=1, \ldots, r s$. Beraz, aurreko azterketa kontuan hartuz, kalkula dezagun 


$$
\mathcal{J}_{G}\left(y_{1}, \ldots, y_{r s}\right)=\frac{1}{4} \sum_{g \in G} y_{1}^{c_{1}(g)} y_{2}^{c_{2}(g)} \cdots y_{r s}^{c_{r s}(g)},
$$

non $c_{j}(g)$ berretzaile bakoitza $g$ simetriaren $j$-ziklo kopurua den.

- 1. kasua: $r$ eta $s$ bikoitiak direnean, $r=2 n, s=2 m$. Argi dagoenez, $c_{1}\left(1_{G}\right)=r s$ eta $c_{2}\left(\sigma_{2}\right)=c_{2}\left(e_{1}\right)=c_{2}\left(e_{3}\right)=r s / 2$.

- 2. kasua: $r$ bakoitia eta $s$ bikoitia direnean, $r=2 n+1$ eta $s=2 m$. Orain, $c_{1}\left(1_{G}\right)=r s, c_{2}\left(\sigma_{2}\right)=c_{2}\left(e_{1}\right)=r s / 2, c_{1}\left(e_{3}\right)=s$ eta $c_{2}\left(e_{3}\right)=$ $=\frac{r s-s}{2}$.

- 3. kasua: $r$ bikoitia eta $s$ bakoitia direnean, $r=2 n$ eta $s=2 m+1$. Matrizea aurreko kasuaren matrize iraulia denez, aurreko egoeraren soluzioan $r$ eta $s$ trukatuz lortuko dugu emaitza.

- 4. kasua: $r$ eta $s$ bakoitiak direnean, $r=2 n+1$ eta $s=2 m+1$.

Kasu honetan, $\quad c_{1}\left(1_{G}\right)=r s, c_{1}\left(e_{1}\right)=r, \quad c_{2}\left(e_{1}\right)=\frac{r s-r}{2}, c_{1}\left(e_{3}\right)=s$, $c_{2}\left(e_{3}\right)=\frac{r s-s}{2}, c_{1}\left(\sigma_{2}\right)=1$ eta $c_{2}\left(\sigma_{2}\right)=\frac{r s-1}{2}$.

2. taula. $a\left(r, s ; t,\left(n_{1}, \ldots, n_{t}\right)\right)$ segidak OEISn

\begin{tabular}{lrlllc}
\hline \multicolumn{1}{c}{$(r, s)$} & \multicolumn{1}{c}{$t$} & \multicolumn{1}{c}{$\left(n_{1}, \cdots, n_{t}\right)$} & OEIS kodea & \multicolumn{1}{c}{ Egilea/k, urtea } & Ref. \\
\hline$(1, s)$ & 2 & $(k, s-k)$ & A034851 & N. J. A. Sloane & $(5)$ \\
$(2, s)$ & 2 & $(k, 2 s-k)$ & A226048 & Y. Yurramendi, 2013 & $(5)$ \\
$(3, s)$ & 2 & $(k, 3 s-k)$ & A226290 & Y. Yurramendi, 2013 & $(5)$ \\
$(4, s)$ & 2 & $(k, 4 s-k)$ & A225812 & Y. Yurramendi, M. Merino, 2013 & $(5)$ \\
$(5, s)$ & 2 & $(k, 5 s-k)$ & A228022 & Y. Yurramendi, M. Merino, 2013 & $(5)$ \\
$(6: 10, s)$ & 2 & $(k 6: 10 s-k)$ & A228165:69 & Y. Yurramendi, M. Merino, 2013 & $(5)$ \\
$(r, s)$ & 2 & $(\lceil r s / 2\rceil,\lfloor r s / 2\rfloor)$ & A283435 & M. Merino, I. Unanue, 2017 & $(5)$ \\
$(r, s)$ & 3 & $\left(\lceil r s / 3\rceil^{k},\lfloor r s / 3\rfloor^{3-k}\right)$ & A286892 & M. Merino, I. Unanue, 2017 & $(5)$ \\
$(r, s)$ & 4 & $\left(\lceil r s / 4\rceil^{k},\lfloor r s / 4\rfloor^{4-k}\right)$ & A287020 & M. Merino, I. Unanue, 2017 & $(5)$ \\
$(r, s)$ & 5 & $\left(\lceil r s / 5\rceil^{k},\lfloor r s / 5\rfloor^{5-k}\right)$ & A287021 & M. Merino, I. Unanue, 2017 & $(5)$ \\
$(r, s)$ & 6 & $\left(\lceil r s / 6\rceil^{k},\lfloor r s / 6\rfloor^{6-k}\right)$ & A287022 & M. Merino, I. Unanue, 2017 & $(5)$ \\
$(r, s)$ & 7 & $\left(\lceil r s / 7\rceil^{k},\lfloor r s / 7\rfloor^{7-k}\right)$ & A287377 & M. Merino, I. Unanue, 2017 & $(5)$ \\
$(r, s)$ & 8 & $\left(\lceil r s / 8\rceil^{k},\lfloor r s / 8\rfloor^{8-k}\right)$ & A287378 & M. Merino, I. Unanue, 2017 & $(5)$ \\
$(r, s)$ & 9 & $\left(\lceil r s / 9\rceil^{k},\lfloor r s / 9\rfloor^{9-k}\right)$ & A287383 & M. Merino, I. Unanue, 2017 & $(5)$ \\
$(r, s)$ & 10 & $\left(\lceil r s / 10\rceil^{k},\lfloor r s / 10\rfloor^{10-k}\right)$ & A287384 & M. Merino, I. Unanue, 2017 & $(5)$ \\
\hline
\end{tabular}

Hortaz, (5) adierazpenean, inbentarioen laburpena dugu. 2. taulan OEISn agertzen diren lotutako segidak kontsulta daitezke (ikusi [3]). Kontuan hartu $a\left(r, s ; t,\left\{n_{1}, \ldots, n_{t}\right\}\right)$ notazioak inbentarioko $x_{1}^{n_{1}} \cdots x_{t}^{n_{t}}$ mo- 
nomioaren koefizientea adierazten duela; $\mathcal{J}_{G}\left(y_{1}, \ldots, y_{r s}\right)=\mathcal{I}_{\Omega}\left(x_{1}, \ldots, x_{t}\right)=$ $\Sigma a\left(r, s ; t,\left\{n_{1}, \ldots, n_{t}\right\}\right) x_{1}^{n_{1}} \cdots x_{t}^{n_{t}}$. Eta $\left(\lceil r s / t\rceil^{k},[r s / t\rfloor^{t-k}\right)$ adierazpenak azaltzen du $t$ koloreak berdin banatuta daudela $r s$ gelaxkatan; hau da, baldin $r s=k \bmod t$ bada, lehenengo $k$ koloreak $\lfloor r s / t\rfloor$ aldiz agertzen dira eta gainontzekoak $\lceil r s / t\rceil$ aldiz. Inbentarioetako mila digituko koefizienteak lortzeko kostu konputazionala dela eta, kopuruen adierazpen esplizituak lortu dira.

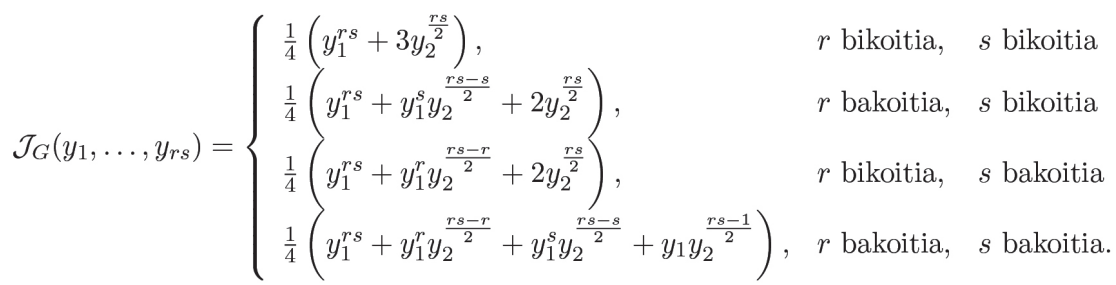

Adibidez, $3 \times 2$ laukiko sare baten eta $t=3$ koloreko inbentarioa hurrengoa da:

$$
\mathcal{I}_{\Omega}=\left(x_{1}, x_{2}, x_{3}\right)=\frac{1}{4}\left(\left(x_{1}+x_{2}+x_{3}\right)^{6}+\left(x_{1}+x_{2}+x_{3}\right)^{2}\left(x_{1}^{2}+x_{2}^{2}+x_{3}^{2}\right)^{2}+2\left(x_{1}^{2}+x_{2}^{2}+x_{3}^{2}\right)^{3}\right) .
$$

Koefiziente guztiak batzen baldin baditugu, lauki-sare ez-baliokideen kopurua lortuko dugu. Mathematica softwarearekin kalkulatuta, [15], 216 lauki-sare ez-baliokide lortu ditugu. Bestalde, kolore bakoitzaren maiztasunak ezagututa, jakin dezakegu zenbat lauki-sare ezbaliokide dauden. Esate baterako, bi kolore behin agerturik eta hirugarrena beste lauki guztietan, 8 lauki-sare ez-baliokide daude; 5 . irudikoak, hain zuzen. Hiru koloreak maiztasun berdinarekin agertuz, 27 ez-baliokide daude. Izan ere, $x_{1} x_{2} x_{3}^{4}$ eta $x_{1}^{2} x_{2}^{2} x_{3}^{2}$ osagaien koefizienteak $\mathcal{I}_{\Omega}\left(x_{1}, x_{2}, x_{3}\right)$ adierazpenean 8 eta 27 baitira.
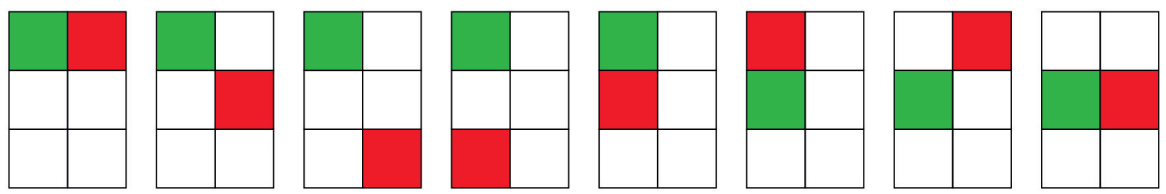

5. irudia. 3 koloreko $3 \times 2$ lauki-sareak: $x_{1} x_{2} x_{3}^{4}$ monomioak ematen dituen matrizeak. 


\section{TALDE DIEDRIKOAREKIKO MATRIZE KARRATU EZ-BALIOKIDEEN KOPURUA}

Kasu honetan, elementuak $r \times r$ matrize karratuen osagaiak dira: $I=\left\{a_{i j}: i, j=1 \cdots r\right\}$. Dakigunez, simetria gehiago hartzen ahal ditugu kontuan azterketa egitean. Orain, matrizeak baliokideak dira, islatzearen eta $\pi / 2$-ren multiploak diren angelutan biratzearen bidez. Zehazki, $G$ taldea karratuaren simetrien taldea izango da, hots, $G=D_{4}$ (ikusi 6. irudia).

$$
\begin{aligned}
& \left(\begin{array}{lll}
a_{11} & a_{12} & a_{13} \\
a_{21} & a_{22} & a_{23} \\
a_{31} & a_{32} & a_{33}
\end{array}\right) \quad\left(\begin{array}{lll}
a_{31} & a_{21} & a_{11} \\
a_{32} & a_{22} & a_{12} \\
a_{33} & a_{23} & a_{13}
\end{array}\right) \quad\left(\begin{array}{lll}
a_{33} & a_{32} & a_{31} \\
\hdashline a_{23} & a_{22} & a_{21} \\
a_{13} & a_{12} & a_{11}
\end{array}\right) \quad\left(\begin{array}{lll}
a_{13} & a_{23} & a_{33} \\
a_{12} & a_{22} & a_{32} \\
a_{11} & a_{21} & a_{31}
\end{array}\right) \\
& \begin{array}{cccc}
1_{G} & \sigma_{1} & \sigma_{2} & \sigma_{3}
\end{array}
\end{aligned}
$$

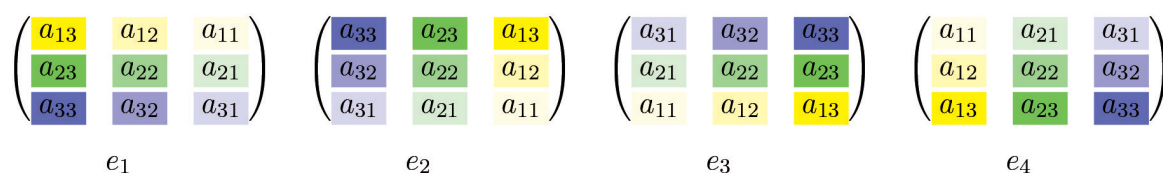

6. irudia. $3 \times 3$ matrizearen gaineko simetriak.

$$
G=\left\{1_{G}, \sigma_{1}, \sigma_{2}, \sigma_{3}, e_{1}, e_{2}, e_{3}, e_{4}\right\}, \text { non honako elementu hauek dauden: }
$$

$1_{G}, G$ taldearen elementu neutroa;

$\sigma_{i}$, matrizearen $\pi / 2 \cdot i$ angeluko biraketa erloju orratzen noranzkoan, hots, $\sigma_{i}=\left(\sigma_{1}\right)^{i}, i=1,2,3$;

$e_{1}$, matrizearen ardatz bertikalarekiko islapena;

$e_{2}$, matrizearen ezkerretik gorako ardatz diagonalarekiko islapena, hots, $e_{2}=\sigma_{1} \circ e_{1} ;$

$e_{3}$, matrizearen ardatz horizontalarekiko islapena, hots, $e_{3}=\sigma_{2} \circ e_{1}$;

$e_{4}$ matrizearen ezkerretik beherako ardatz diagonalarekiko islapena, hots, $e_{4}=\sigma_{3} \circ e_{1}$.

\subsection{Orbiten kalkulua}

Aurreko egoeraren pausu berei jarraituz, lehenik eta behin adieraz ditzagun $G$-ko elementuak zikloen biderkadura gisa. Horretarako, $r$ balioaren bikoitasuna kontuan hartu behar dugu. Biraketa guztiak $\sigma_{1}$ biraketaren berretzaileak direnez, $\sigma_{1}$ biraketa baino ez dugu adieraziko zikloen biderkadura gisa. Orain, Burnsideren 7. lema erabiliz, zenbatu ditzagun $G$-rekiko I-ren orbita desberdinen kopurua.

$$
\mid\{G \text {-rekiko } I \text {-ren orbitak }\} \mid=\frac{1}{8}\left(\sum_{i=1}^{4}\left|F\left(\sigma_{i}\right)\right|+\sum_{i=1}^{4}\left|F\left(e_{i}\right)\right|\right) .
$$


Lauki-sareko patroiak kalkulatzea, Pólyaren teoriaren eskutik

- 1. kasua: $r$ bikoitia denean, $r=2 n$. Egoera honetan, $e_{1}$ eta $e_{3}$ islapenen elementu guztiak transposizio disjuntuen biderkadura gisa adieraz daitezke. Beste bi islapenek, ordea, diagonal ardatzen osagaiak finko utziko dituzte, eta beste osagaiak transposizio disjuntuen biderkadura gisa adieraz daitezke. Bestalde, biraketa bakoitza 4-zikloz edo 2-zikloz osatuta egongo da.

$$
\begin{gathered}
F\left(1_{G}\right)=I ; F\left(\sigma_{1}\right)=F\left(\sigma_{2}\right)=F\left(\sigma_{3}\right)=F\left(e_{1}\right)=F\left(e_{3}\right)=\varnothing ; \\
F\left(e_{2}\right)=\left\{a_{1 r}, a_{2(r-1)}, \ldots, a_{r 1}\right\} \text { eta } F\left(e_{4}\right)=\left\{a_{11}, a_{22}, \ldots, a_{r r}\right\} \text { direnez, } \\
\mid\{G \text {-rekiko } I \text {-ren orbitak }\} \mid=\frac{r^{2}+2 r}{8} .
\end{gathered}
$$

- 2. kasua: $r$ bakoitia denean, $r=2 n+1$. Egoera honetan, islapenek errenkada, zutabe edo diagonal bateko osagaiak finko utziko dituzte, eta beste osagaiak transposizio disjuntuen biderkadura gisa adieraziko dituzte. Bestalde, biraketa guztiek matrizearen zentroko osagaia finko utziko dute, eta besteak, aurreko kasuaren antzera, ziklo disjuntuetan adieraziko dituzte.

$$
\begin{gathered}
F\left(1_{G}\right)=I ; F\left(\sigma_{1}\right)=F\left(\sigma_{2}\right)=F\left(\sigma_{3}\right)=\left\{a_{(n+1)(n+1)}\right\} ; \\
F\left(e_{1}\right)=\left\{a_{1(n+1)}, a_{2(n+1)}, \ldots, a_{r(n+1)}\right\} ; F\left(e_{2}\right)=\left\{a_{1 r}, a_{2(r-1)}, \ldots, a_{r_{1}}\right\} ; \\
F\left(e_{3}\right)=\left\{a_{(n+1)_{1}}, a_{(n+1)_{2}}, \ldots, a_{(n+1)_{r}}\right\} \text { eta } F\left(e_{4}\right)=\left\{a_{11}, a_{22}, \ldots, a_{r r}\right\} \text { direnez, } \\
\mid\{G \text {-rekiko } I \text {-ren orbitak }\} \mid=\frac{r^{2}+4 r+3}{8} .
\end{gathered}
$$

\section{2. $r \times r$ matrizeen kolorazio ez-baliokideen kopurua}

Orain, kontsidera ditzagun $t$ koloreak. Kalkula dezagun $\operatorname{Col}_{t}(I)$-ko kolorazio ez-baliokideen kopurua $G$-ren gainean, Burnsideren kolorazioetarako 10 . lema erabiliz.

$$
b(r ; t)=\left|\left\{\begin{array}{c}
G \text {-ren gaineko } \operatorname{Col}_{t}(I)-\mathrm{ko} \\
\text { kolorazio ez baliokideak }
\end{array}\right\}\right|=\frac{1}{8} \sum_{i=1}^{r^{2}}\left|\left\{\begin{array}{c}
i \text { zikloko } \\
G \text {-kosimetriak }
\end{array}\right\}\right| t^{i}
$$

- 1. kasua: $r$ bikoitia denean, $r=2 n$.

- $1_{G}-\mathrm{k}$ osagai guztiak finko uzten ditu. Beraz, $r^{2}$ 1-zikloz osatuta dago: $t^{r^{2}}$.

- $\sigma_{1}$ eta $\sigma_{3}$ biraketak puntu finkorik ez duten 4-ziklo disjuntuen biderkadura bezala adierazten direnez, $r^{2} / 4$ zikloz osatuta daude: $t^{r^{2 / 4}}$. 
- $\sigma_{2}, e_{1}$ eta $e_{3}$ simetriak puntu finkorik ez duten transposizio disjuntuen biderkadura bezala adierazten direnez, $r^{2} / 2$ zikloz osatuta daude: $t^{r^{2} / 2}$.

- $e_{2}$ eta $e_{4}$ islapenek diagonal bat finko uzten dute (islapen-ardatzaren osagaiak), eta beste osagai guztiak transposizio disjuntuetan banatzen dira. Beraz, $r+\frac{r^{2}-r}{2}=\frac{r^{2}+r}{2}$ ziklo disjuntuz osatutako aplikazioak dira: $t^{\frac{r^{2}+r}{2}}$.

- 2. kasua: $r$ bakoitia denean, $r=2 n+1$.

- $1_{G}$ aplikazioak osagai guztiak finko uzten ditu: $t^{2}$.

- $\sigma_{1}$ eta $\sigma_{3}$ biraketek matrizearen zentroko osagaia finko uzten dute $\left(a_{(n+1)(n+1)}\right.$, hain zuzen ere), eta beste osagai guztiak 4-ziklo disjuntuetan aurkitzen dira. Beraz, $1+\frac{r^{2}-1}{4}=\frac{r^{2}+3}{4}$ zikloz osatuta daude: $t^{\frac{r^{2}+3}{4}}$.

- $\sigma_{2}$ aplikazioak matrizearen zentroko osagaia finko uzten du, eta beste osagai guztiak transposizio disjuntuetan banatzen ditu. Beraz, $1+\frac{r^{2}-1}{2}=\frac{r^{2}+1}{2}$ zikloz osatuta dago: $t^{\frac{r^{2}+1}{2}}$.

- Islapenek matrizearen errenkada, zutabe edo diagonal bat finko uzten dute, eta beste osagai guztiak transposizio disjuntuetan banatzen dira. Beraz, $r+\frac{r^{2}-r}{2}=\frac{r^{2}+r}{2}$ zikloz osatuta daude: $t^{\frac{r^{2}+r}{2}}$.

Ondorioz, (6) adierazpenean formulen laburpena dugu:

$$
b(r ; t)= \begin{cases}\frac{1}{8}\left(t^{r^{2}}+2 \cdot t^{\frac{r^{2}}{4}}+3 \cdot t^{\frac{r^{2}}{2}}+2 \cdot t^{\frac{r^{2}+r}{2}}\right), & r \text { bikoitia } \\ \frac{1}{8}\left(t^{r^{2}}+2 \cdot t^{\frac{r^{2}+3}{4}}+t^{\frac{r^{2}+1}{2}}+4 \cdot t^{\frac{r^{2}+r}{2}}\right), & r \text { bakoitia. }\end{cases}
$$

Ohartu $t=2$ denean (bi kolore erabiliz) matrize karratu ez-baliokideen kopuruak [1] artikuluan lortutako emaitzekin bat datozela, hots, (2) adierazpenekin. Adibidez, 7. irudian $D_{4}$-rekiko $2 \times 2$ matrize bitar ez-baliokideak ikusten dira. 3. taulan OEISko segidak kontsulta daitezke (ikusi [3]); taularen beheko segidak lan honen ondorio dira. 
3. taula. $b(r ; t)$ segidak OEISn.

\begin{tabular}{cccll}
\hline$(r)$ & $t$ & OEIS kodea & \multicolumn{1}{c}{ Egileak, urtea } & Ref. \\
\hline$(r)$ & 2 & A054247 & V. Jovovic, 2000 & $(2)$ \\
$(r)$ & 3 & A054739 & V. Jovovic, 2000 & $(6)$ \\
$(r)$ & 4 & A054751 & V. Jovovic, 2000 & $(6)$ \\
$(r)$ & 5 & A054752 & V. Jovovic, 2000 & $(6)$ \\
$(r)$ & 6 & A286392 & M. Merino, I. Unanue, Y. Yurramendi, 2017 & $(6)$ \\
$(r)$ & 7 & A286393 & M. Merino, I. Unanue, Y. Yurramendi, 2017 & $(6)$ \\
$(r)$ & 8 & A286394 & M. Merino, I. Unanue, Y. Yurramendi, 2017 & $(6)$ \\
$(r)$ & 9 & A286396 & M. Merino, I. Unanue, Y. Yurramendi, 2017 & $(6)$ \\
$(r)$ & 10 & A286397 & M. Merino, I. Unanue, Y. Yurramendi, 2017 & $(6)$ \\
\hline
\end{tabular}
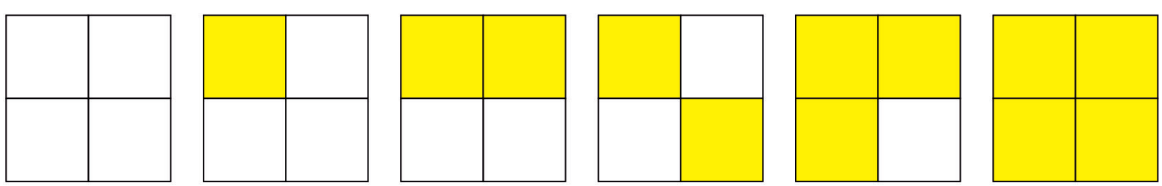

7. irudia. $b(2 ; 2)=6$ aukera $D_{4}$-rekiko $2 \times 2$ matrize bitarrak adierazteko.

\section{3. $r \times r$ matrizeen kolorazioetarako inbentarioa}

Azkenik, kontsidera dezagun $\Omega G$-ren gaineko $\operatorname{Col}_{t}(I)$-ko kolorazio ezbaliokideen multzoa. Kalkula dezagun $\mathcal{I}_{\Omega}\left(x_{1}, \ldots, x_{t}\right)$. Horretarako, Pólyaren 14. teorema erabiliko dugu, aurretik egindako $G$-ko elementuen azterketa kontuan hartuz.

(7) adierazpenean inbentarioen laburpena dugu. 4. taulan OEISn agertzen diren segidak kontsulta daitezke (ikusi [3]); taularen beheko segidak lan honen ondorio dira. Ohartu $b\left(r ; t,\left(n_{1}, \ldots, n_{t}\right)\right)$ notazioak inbentarioan $x_{1}^{n_{1}} \cdots x_{t}^{n_{t}}$ monomioaren koefizientea adierazten duela: $\mathcal{J}_{G}\left(y_{1}, \ldots, y_{r^{2}}\right)=\mathcal{I}_{\Omega}\left(x_{1}, \ldots, x_{t}\right)=\Sigma b\left(r ; t,\left\{n_{1}, \ldots, n_{t}\right\}\right) x_{1}^{n_{1}} \cdots x_{t}^{n_{t}}$. Horrenbestez,

$$
\mathcal{J}_{G}\left(y_{1}, \ldots, y_{r^{2}}\right)= \begin{cases}\frac{1}{8}\left(y_{1}^{r^{2}}+2 y_{1}^{r} y_{2}^{\frac{r^{2}-r}{2}}+3 y_{2}^{\frac{r^{2}}{2}}+2 y_{4}^{\frac{r^{2}}{4}}\right), & r \text { bikoitia } \\ \frac{1}{8}\left(y_{1}^{r^{2}}+4 y_{1}^{r} y_{2}^{\frac{r^{2}-r}{2}}+y_{1} y_{2}^{\frac{r^{2}-1}{2}}+2 y_{1} y_{4}^{\frac{r^{2-1}}{4}}\right), & r \text { bakoitia. }\end{cases}
$$


4. taula. $b\left(r ; t,\left(n_{1}, \ldots, n_{t}\right)\right)$ segidak OEISn.

\begin{tabular}{cclclc}
\hline$(r)$ & $t$ & \multicolumn{1}{c}{$\left(n_{1}, \ldots, n_{t}\right)$} & OEIS kodea & \multicolumn{1}{c}{ Egileak, urtea } & Ref. \\
\hline$(r)$ & 2 & $\left(\left\lceil r^{2} / 2\right\rceil,\left\lfloor r^{2} / 2\right\rfloor\right)$ & A082963 & V. Jovovic, 2003 & $(7)$ \\
$(r)$ & 3 & $\left(\left\lceil r^{2} / 3\right\rceil^{k},\left\lfloor r^{2} / 3\right\rfloor^{3-k}\right)$ & A286447 & M. Merino, I. Unanue, 2017 & $(7)$ \\
$(r)$ & 4 & $\left(\left\lceil r^{2} / 4\right\rceil^{k},\left\lfloor r^{2} / 4\right\rfloor 4^{-k}\right)$ & A286525 & M. Merino, I. Unanue, 2017 & $(7)$ \\
$(r)$ & 5 & $\left(\left\lceil r^{2} / 5\right\rceil^{k},\left\lfloor r^{2} / 5\right\rfloor^{5-k}\right)$ & A286526 & M. Merino, I. Unanue, 2017 & $(7)$ \\
$(r)$ & 6 & $\left(\left\lceil r^{2} / 6\right\rceil^{k},\left\lfloor r^{2} / 6\right\rfloor^{6-k}\right)$ & A287239 & M. Merino, I. Unanue, 2017 & $(7)$ \\
$(r)$ & 7 & $\left(\left\lceil r^{2} / 7\right\rceil^{k},\left\lfloor r^{2} / 7\right\rfloor^{7-k}\right)$ & A287245 & M. Merino, I. Unanue, 2017 & $(7)$ \\
$(r)$ & 8 & $\left(\left\lceil r^{2} / 8\right\rceil^{k},\left\lfloor r^{2} / 8\right\rfloor^{8-k}\right)$ & A287249 & M. Merino, I. Unanue, 2017 & $(7)$ \\
$(r)$ & 9 & $\left(\left\lceil r^{2} / 9\right\rceil^{k},\left\lfloor r^{2} / 9\right\rfloor^{9-k}\right)$ & A287250 & M. Merino, I. Unanue, 2017 & $(7)$ \\
$(r)$ & 10 & $\left(\left\lceil r^{2} / 10\right\rceil^{k},\left\lfloor r^{2} / 10\right\rfloor^{10-k}\right)$ & A287261 & M. Merino, I. Unanue, 2017 & $(7)$ \\
\hline
\end{tabular}

Adibidez, $3 \times 3$ ko lauki-sare baten eta $t=3$ koloreko inbentarioa hurrengoa da:

$$
\begin{gathered}
\mathcal{I}_{\Omega}\left(x_{1}, x_{2}, x_{3}\right)=\frac{1}{8}\left(\left(x_{1}+x_{2}+x_{3}\right)^{9}+4\left(x_{1}+x_{2}+x_{3}\right)^{3}\left(x_{1}^{2}+x_{2}^{2}+x_{3}^{2}\right)^{3}+\right. \\
\left.+\left(x_{1}+x_{2}+x_{3}\right)\left(x_{1}^{2}+x_{2}^{2}+x_{3}^{2}\right)^{4}+2\left(x_{1}+x_{2}+x_{3}\right)\left(x_{1}^{4}+x_{2}^{4}+x_{3}^{4}\right)^{2}\right) .
\end{gathered}
$$

Kasu honetan, koefiziente guztien batura 2862 da. Bestalde, bi kolore behin agerturik eta hirugarren kolorea beste lauki guztietan, 12 lauki-sare ez-baliokide daude; 8. irudikoak, hain zuzen ere. Hiru koloreak maiztasun berarekin agertuz, 228 ez-baliokide daude. Izan ere, $\mathcal{I}_{\Omega}\left(x_{1}, x_{2}, x_{3}\right)$-ren $x_{1} x_{2} x_{3}^{7}$ eta $x_{1}^{3} x_{2}^{3} x_{3}^{3}$ osagaien koefizienteak 12 eta 228 baitira.
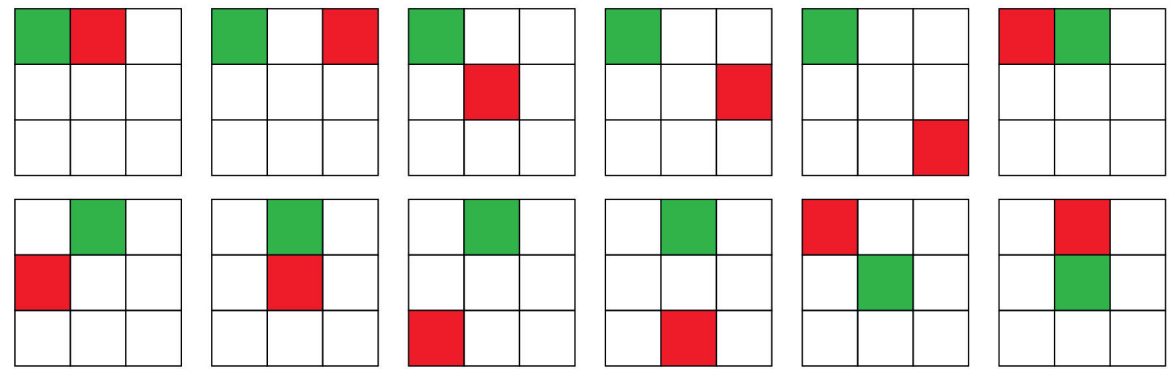

8. irudia. 3 koloreko $3 \times 3$ lauki-sareak: $x_{1} x_{2} x_{3}^{7}$ monomioak ematen dituen matrizeak. 
Lauki-sareko patroiak kalkulatzea, Pólyaren teoriaren eskutik

\section{ONDORIOAK}

Problema bat aztertzeko hiru bide matematiko azaltzen dira: konputazio hutsezko bide esperimentala eta indukzioa (ikusi [1]); oinarrizko konbinatoriaren arrazoinamendu deduktiboa (ikusi [2]), eta teoria orokor baten aplikatzea (hain zuzen, lan honetan ibilitakoa). Artikulua, aparkaleku-txartelak diseinatzeko problemarekin hasi genuen, baina aplikazio ugari daude. Pólyaren hasierako lanak kimika arloan aplikatuak ziren (ikusi [5, 6]); izan ere, matrize orokorren kasuan, lerro bakarra dugunean alkanoak edo parafinak azaltzen dira. Matrize karratuen kasuan, bederatzi lerro bederatzi elementurekin koloreztatzeko problema sudokuari lotuta dago (ikusi [16], eta sudokuak zenbatzeko problemen inguruan horretan agertutako erreferentziak).

\section{ESKER ONAK}

Eskerrak eman nahi dizkiegu UPV/EHUko UFI11/46 Prestakuntza eta Ikerketa Unitateari eta GIU17/011 Ikerketa Taldeari eta Ekonomia eta Lehiakortasun Espainiako Ministerioko MTM2015-65317-P proiektuari. Halaber, hizkuntza-aholkulariei, begirale teknikoari eta, bereziki, Gustavo A. Fernández Alcober editoreari eskertzen diegu egindako lana.

\section{ERREFERENTZIAK}

[1] YURRAMENDI Y. 2013. «Matematika esperimentalaren adibide bat: Lauki sareko patroi bitarren kopuruaren kalkulua,» EKAIA, 26, 325-348.

[2] MERINO M. eta YURRAMENDI Y. 2014. «Lauki sareko patroi bitarren kalkulua, oinarrizko konbinatoriaren eskutik,» EKAIA, 27, 237-262.

[3] SLOANE N.J.A. (ed.), «The On-Line Encyclopedia of Integer Sequences.» Website, eguneratze-data: 2017-05-12. http://oeis.org.

[4] REDFIELD J. H. 1927. «The Theory of Group-Reduced Distributions,» Amer. J. Math., 49, 433-455.

[5] PÓLYA G. 1937. «Kombinatorische Anzahlbestimmungen für Gruppen, Graphen und chemische Verbindungen,» Acta Mathematica, 68, 145-254.

[6] PÓLYA G. eta READ R. C. 1987. Combinatorial enumeration of groups, graphs, and chemical compounds. Springer-Verlag, New York. Pólya's contribution translated from the German by Dorothee Aeppli.

[7] COHEN D. I. A. 1978. Basic Techniques of Combinatorial Theory. John Wiley \& Sons.

[8] GRIMALDI R. P. 1998. Matemáticas Discreta y Combinatoria. Una introducción con aplicaciones. Addison Wesley Iberoamericana, S.A. 
[9] FERNÁNDEZ P. eta FERNÁNDEZ J. L. 2016. El Discreto Encanto de la Matemática. UAM.

[10] HUMPHREYS J. 1996. A Course in Group Theory. Oxford University Press.

[11] ROTMAN J. 1984. An Introduction to the Theory of Groups. Springer-Verlag, New York.

[12] ROSE H. 2009. A Course on Finite Groups. Springer-Verlag, New York.

[13] BURNSIDE W. 1897. Theory of Groups of Finite Order. Cambridge University Press.

[14] FROBENIUS F. G. 1887. «Ueber die Congruenz nach einem aus zwei endlichen Gruppen gebildeten Doppelmodul,» Crelle, 101, 273-299.

[15] Wolfram, «Mathematica.» Website, eguneratze-data: 2017-05-12. https:// www. wolfram.com/mathematica/.

[16] MERINO M. 2011. «Sudokua: denbora-pasa edo Zientzia?,» EKAIA, 24, 185-203. 